\title{
Arthroplasty for Treating Traumatic Metacarpophalangeal Joint Defects: A Retrospective Study Over Three Years
}

\author{
Fei Xie \\ Xianfeng Lan \\ Jingui Lin
}

Department of Hand Surgery, Fuzhou Second Hospital Affiliated to Xiamen University, Fuzhou, Fujian, 350004,

People's Republic of China
Correspondence: Jingui Lin

Department of Hand Surgery, Fuzhou Second Hospital Affiliated to Xiamen University, Shangteng Street, Cangshan District, Fuzhou, 350004, People's

Republic of China

$\mathrm{Tel} / \mathrm{Fax}+86 \quad 17720746077$

Email linjinguishouwaike@163.com
Background: Bone loss at the metacarpophalangeal joint (MCP) after trauma is difficult to treat.

Objective: We aimed to investigate the effectiveness of Swanson's arthroplasty and the reason for implant fracture.

Methods: We retrospectively analyzed the data of 175 patients who underwent emergency MCP arthroplasty between 2013 and 2016. Some patients used a orthosis to limit the radioulnar movement of the metacarpal joint for eight weeks after surgery (Group A), while the other patients underwent only hand rehabilitation after surgery (Group B). The basic information and perioperative data of the patients were compared. The patients were followed up clinically for an average of $65 \pm 19$ months. Postoperative and follow-up complications and functional parameters were recorded and compared. Stress model of implant fracture had been analyzed in order to mark the frequent area.

Results: A total of 162 patients were followed up, 4 of whom were lost to follow-up completely and 9 of whom were followed up by telephone only. There were 11 and 26 implant fractures in groups $\mathrm{A}$ and $\mathrm{B}$, respectively $(\mathrm{P}=0.019)$, and the degrees of radioulnar movement were $2 \pm 1^{\circ}$ and $7 \pm 4^{\circ}$, respectively $(\mathrm{P}<0.01)$. The disabilities of the arm, shoulder, and hand (DASH) score and MCP joint range of motion (ROM) did not significantly differ. Conclusion: The effect of Swanson's arthroplasty for bone loss at MCP joint is useful. The radioulnar stress may be the reason for implant fracture. Joint orthosis can reduce the incidence of implant fractures.

Keywords: metacarpophalangeal joint defects, Swanson's arthroplasty, stress model, hand surgery

\section{Introduction}

Bone loss at the metacarpophalangeal (MCP) joint after trauma is difficult to treat. Arthritis and pain often occur after MCP joint injuries. ${ }^{1}$ Preserving joint movement is challenging in both the short and long term. In addition, long-term fixation after bone stabilization can lead to the adhesion of tendons and soft tissue, limiting movement. ${ }^{2}$ In such cases, MCP surgery may be complicated by nonunion, bone defects and hand dysfunction.

Swanson's MCP arthroplasty has been shown to be successful in the treatment of posttraumatic MCP arthritis and rheumatoid arthritis, but this procedure is related to a high rate of late failure, delayed infection, synovitis, and implant fractures. $^{2-5}$ Previous studies have shown that the key to emergency MCP joint 
replacement is to prevent infection, and second-stage surgery is often performed when the infection is severe. ${ }^{6,7}$ With the development of drug research and the advancements of antibiotics, arthroplasty can relieve the problems of stiffness and capsular contractures when it is performed early. However, there are still some complications, such as early fractures of the implant, progressive stiffness of the hand and silicone synovitis. ${ }^{8,9}$ Recently, Roh et $\mathrm{al}^{10}$ found that MCP extension orthoses for sagittal band injuries lead to satisfactory results in patients. We thought that joint orthosis which have the same function with MCP extension orthoses that limited to the radioulnar side may be useful for reducing lateral stress. In the revision surgery, we found that the fracture line of prosthesis appeared in the lateral and dorsal sides, and the lateral side was more, maybe the lateral stress would increase the probability of implant fracture. Indeed, Implant fractures commonly cause hand function loss and reducing this complication in particular is important for preserving hand function. We aimed to investigate the effectiveness of Swanson's arthroplasty and the reason for implant fracture.

\section{Methods}

With the approval of our agency review committee, we reviewed the data of 175 patients who underwent emergency Swanson's joint MCP arthroplasty between 2013 and 2016. MCP arthroplasty was used to treat MCP joints bone defects in patients without loss of blood supply. We only included the patients with index or middle finger injury. The patient's genal information, dominant hand, injury pattern, and any complications that occurred during or after surgery were recorded. The final range of motion $(\mathrm{ROM})$, grip index (= grip strength $(\mathrm{kg}) /$ weight $(\mathrm{kg}) \times 100)$ and disabilities of the arm, shoulder, and hand (DASH) score were measured at 3 months and at the final follow-up ( $>3$ years). Implant fracture as a signal of the end of follow-up. Complete loss of function was an indicator of an implant fracture, X-ray was used for patients who were difficult to judge.

All procedures were performed by senior surgeons, and the technique described by Swanson was slightly modified. ${ }^{11}$ All patients underwent extensor tendon repair, and 13 underwent flexor tendon repair. Most patients had adequate collateral ligament tissue for primary repair. All patients received antibiotic therapy after the operation and were placed in both resting (Figure 1) and dynamic (Figure 2) orthoses after the postoperative dressing was removed, and coordinated movements of

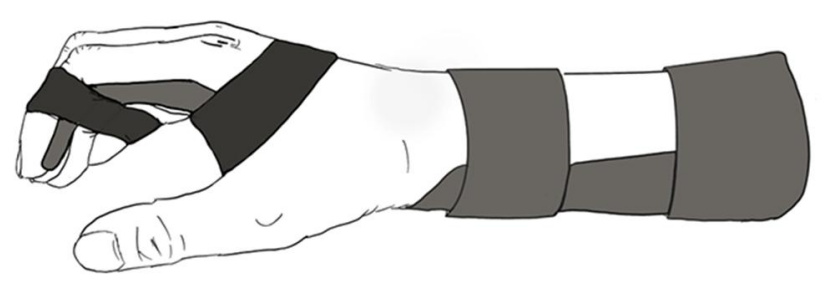

Figure I Resting orthosis.

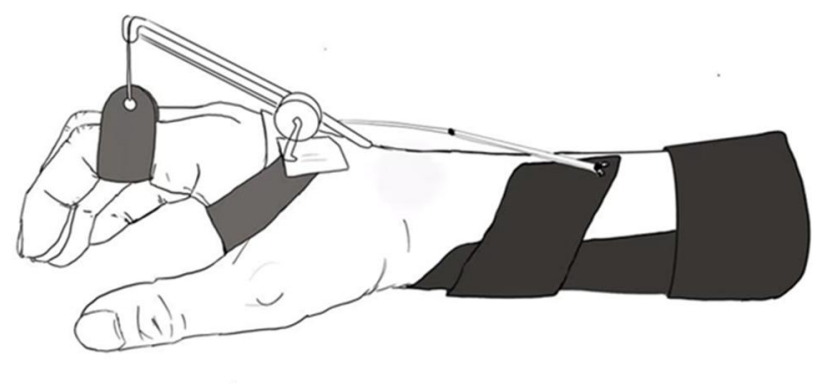

Figure 2 Dynamic orthosis.

the wrist and MCP joints were allowed for 4 weeks. Then, rehabilitation was started. We transferred the postoperative patients to the rehabilitation department, and the rehabilitation department randomly assigned the patients to two different doctors that did not know the preoperative condition of patient. A rehabilitation doctor used a joint orthosis (Figure 3) to limit the radioulnar movement of the MCP joint for 8 weeks (Group A) after the resting and dynamic orthosis was used; the other doctor administered only hand rehabilitation, and full unprotected motion was allowed at 12 weeks (Group B).

Data analysis was performed using SPSS 23.0 (SPSS, limited). The Kolmogorov-Smirnov test was conducted to determine whether the data were normally distributed. The normally distributed data are expressed as means and standard deviations. The non normally distributed data are expressed as intermediate values and ranges. Significant differences between groups were identified through independent sample $\mathrm{T}$ and chi-square tests. The functional and DASH scores were analyzed by correlation analysis. Pro/ Engineer Wildfire 5.0 software was used to model the fault implant and analyze the fracture-prone parts. 


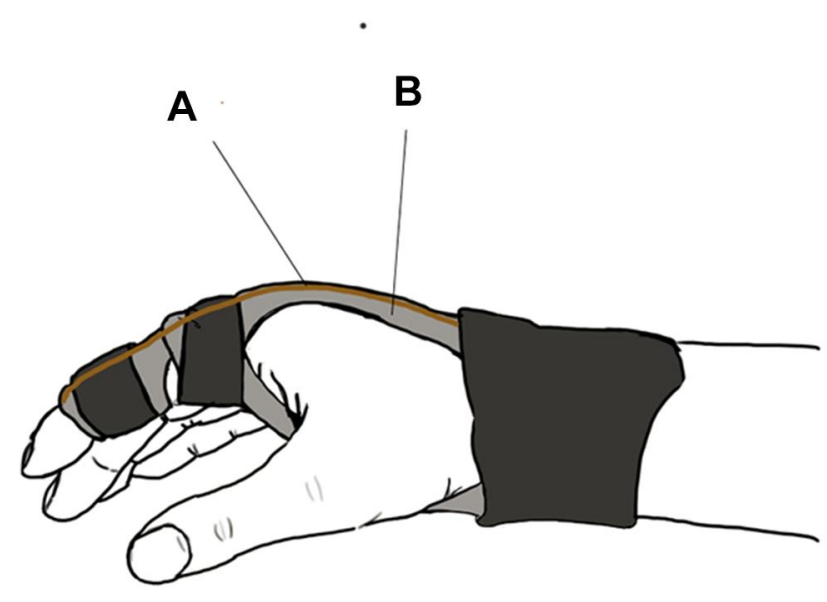

Figure 3 Orthosis of limit the radioulnar movement. (A) Elastic plastic material displayed in yellow. (B) Rigid material displays in gray and has a pully at MCP.

\section{Results}

A total of 162 patients were followed up, 4 of whom were lost to follow-up completely (two cases in each group) and 9 of whom were followed up by telephone only (all of them have normal function but only include postoperative data, 6 cases in Group A, 3 cases in Group B). The patients were followed up clinically for an average of 65 \pm 19 months. Three patients had early wound infections that were treated with debridement. Thirty-six patients developed implant fractures at an average of 68 months (range from 100 to 36 months).

The preoperative data are shown in Table 1. The postoperative and follow-up functional results of the two groups are shown in Table 2. After excluding the patients of implant fracture, 71 cases included in Group A, 91 cases included in Group B. The follow-up ROM values, grip index values and functional scores (DASH scores were reduced) were significantly higher than the postoperative values in both groups $(\mathrm{P}<0.05, \mathrm{P}<0.05, \mathrm{P}<0.05$, respectively).

The correlations between the MCP joint ROM and grip index with the DASH scores are shown in Figures 4 and 5. Postoperatively, the DASH scores were significantly correlated with the MCP joint ROM and grip index, which showed a linear relationship $\left(\mathrm{R}^{2}=0.570\right.$ and $\mathrm{R}^{2}=0.684$, respectively). The typical implant fracture models are shown in Figures 6 and 7. The stress model is shown in Figure 8 .
Table I Preoperative Data

\begin{tabular}{|c|c|c|c|}
\hline & Group A & Group B & $P$ value \\
\hline Age (year) & $42 \pm 12$ & $39 \pm 11$ & 0.09 \\
\hline BMI $\left(\mathrm{kg} / \mathrm{m}^{2}\right)$ & $24.7 \pm 3.4$ & $25.3 \pm 3.6$ & 0.25 \\
\hline Female: male (case) & 10: 69 & 13: 83 & 0.86 \\
\hline Dominant hand & 48 [60.8\%] & $56[58.3 \%]$ & 0.75 \\
\hline \multicolumn{4}{|l|}{ Mechanism of injury } \\
\hline Incised injury & 32 & 43 & 0.10 \\
\hline Crush injury & 25 & 24 & \\
\hline Twist injury & 14 & 20 & \\
\hline Explosive injury & 8 & 9 & \\
\hline \multicolumn{4}{|l|}{ Finger } \\
\hline Index & 39 & 39 & 0.15 \\
\hline Middle & 40 & 57 & \\
\hline
\end{tabular}

Abbreviations: Group A, rehabilitation+ Joint orthosis; Group B, rehabilitation only; BMI, body mass index.

Table 2 Postoperative and Follow-Up Function of the Two Groups

\begin{tabular}{|l|l|l|l|}
\hline Item & Group A & Group B & P \\
\hline Implant fracture (case) & 10 & 26 & $<0.05$ \\
\hline Postoperation DASH scores & $48.9 \pm 17.1$ & $46.3 \pm 173$ & 0.339 \\
\hline Follow-up DASH scores & $42.9 \pm 25.2$ & $46.8 \pm 28.7$ & 0.329 \\
\hline Postoperation MCP joint ROM $\left(^{\circ}\right)$ & $37.0 \pm 14.7$ & $38.7 \pm 15.6$ & 0.470 \\
\hline Follow-up MCP joint ROM $\left(^{\circ}\right)$ & $51.7 \pm 15.2$ & $53.8 \pm 15.1$ & 0.369 \\
\hline Postoperation Grip index & $62.1 \pm 17.4$ & $59.8 \pm 17.1$ & 0.101 \\
\hline Follow-up Grip index & $53.4 \pm 17.1$ & $56.7 \pm 12.8$ & 0.377 \\
\hline Abduction angle $\left(^{\circ}\right)$ & $6.6 \pm 3.9$ & $1.7 \pm 1.4$ & $<0.01$ \\
\hline
\end{tabular}

Abbreviations: Group A, rehabilitation + Joint orthosis; Group B, rehabilitation only; DASH, disabilities of the arm, shoulder, and hand; MCP, metacarpophalangeal; ROM, range of motion.

\section{Discussion}

MCP joints are important for function, and damage can lead to severe disability. Intra-articular injuries combined with bone and cartilage injuries are particularly difficult to treat. The treatments for complex, untreatable MCP fractures include primary joint arthrodesis, ${ }^{12}$ replacement ${ }^{13-15}$ and vascularized joint metastasis. ${ }^{16}$ Another option is MCP arthroplasty. Swanson's implant is usually used for finger joint replacement. This is a successful treatment for 


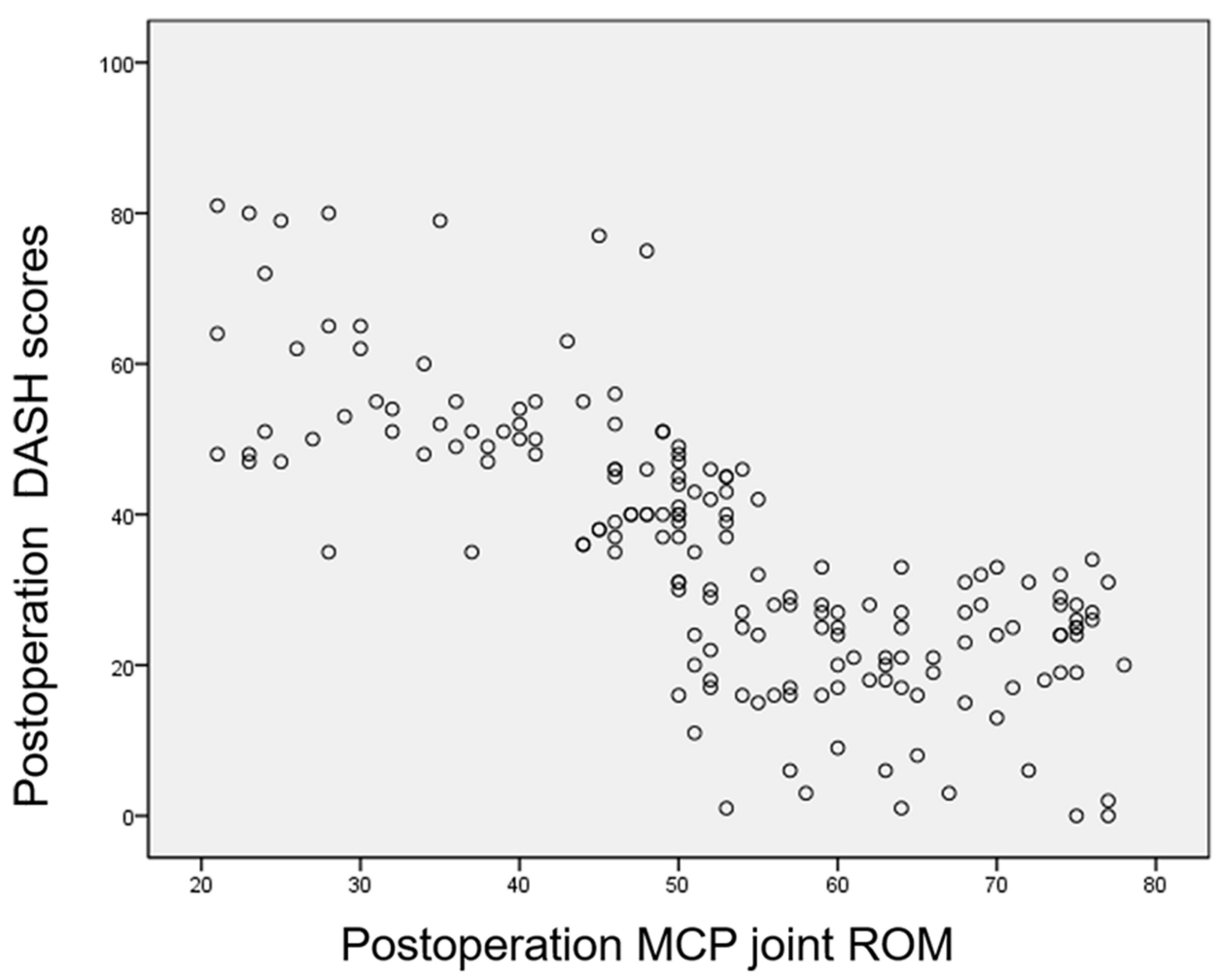

Figure 4 Correction between DASH scores and MCP joint ROM at postoperation.

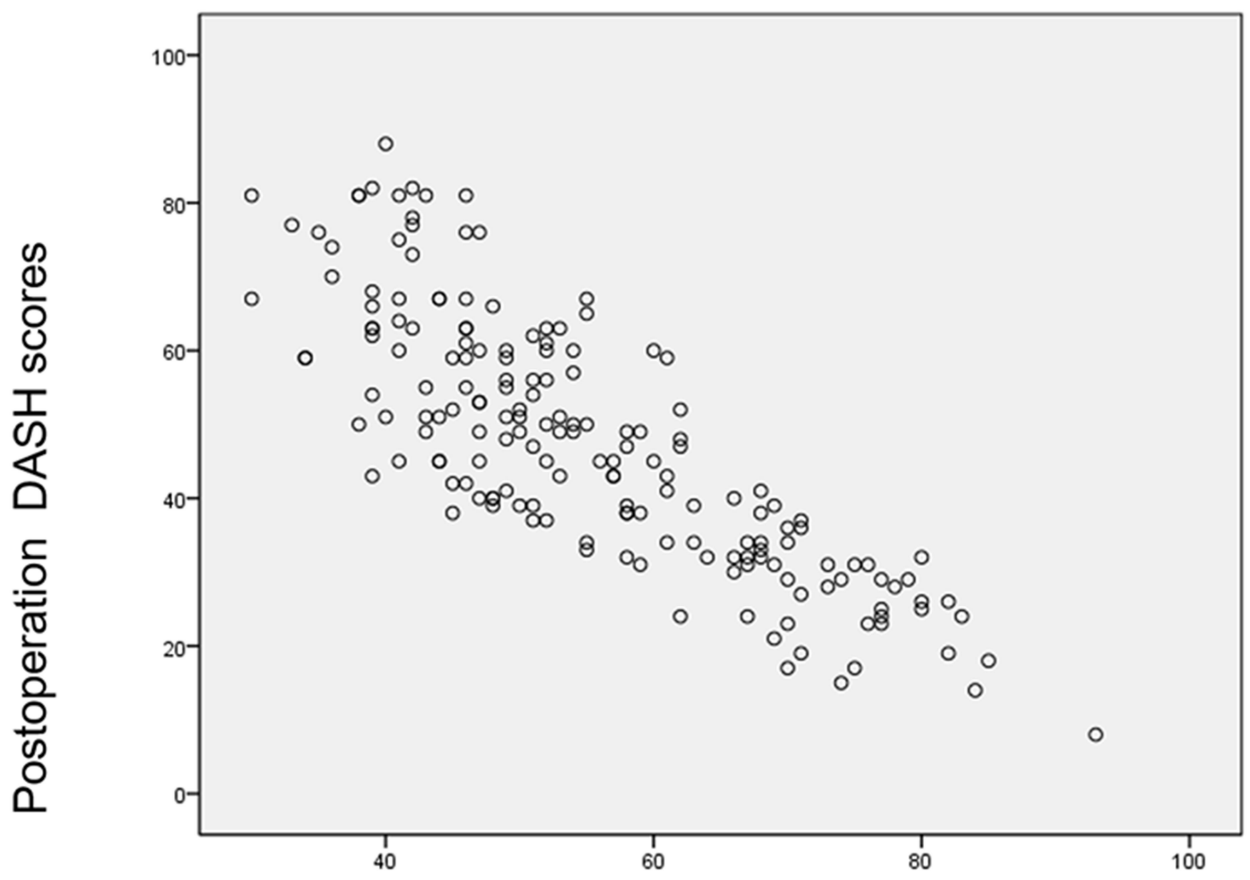

Grip index

Figure 5 Correction between DASH scores and grip index at postoperation. 


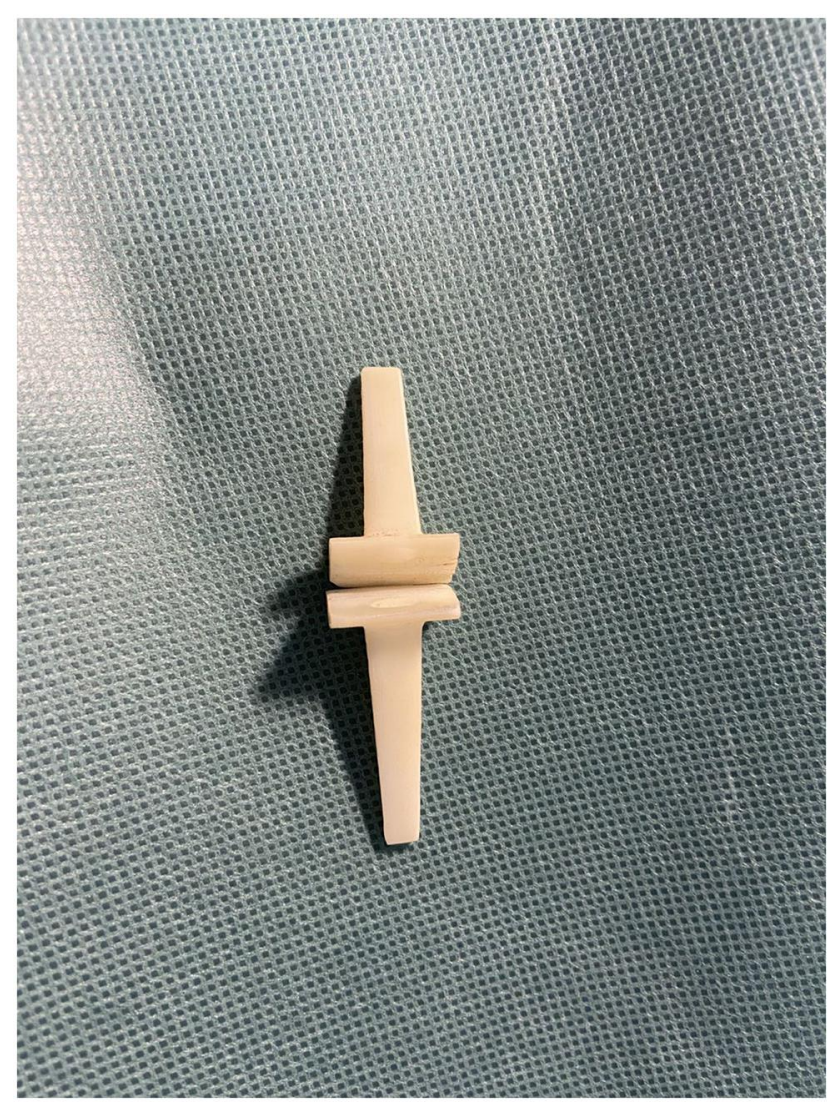

Figure 6 Typical implant fracture models in group A.

patients with osteoarthritis and rheumatoid arthritis. The treatment is successful because Swanson's joints provide a sufficient ROM and have good biocompatibility with the MCP joint. In 2012, Chung et $\mathrm{al}^{17}$ followed 67 patients with rheumatoid arthritis for at least 3 years. The authors found that the patients who underwent silicone metacarpophalangeal arthroplasty had good results and continued to have better hand outcomes than did comparable nonsurgically treated patients. One patient had an infection, and 2 patients required revision due to ulnar drift and implant fracture. In 2013, Neral et $\mathrm{al}^{18}$ reported the results of 30 out of 38 patients who underwent a combined replacement operation over an average follow-up time of 56 months. In that study, straight stems and anatomical implants were used. Similar to the authors of previous studies, those authors reported that the patients were very satisfied. The authors reported significant improvements in ROM, pain, and DASH scores, but they also reported an $11 \%$ rate of implants fracture and a $21 \%$ rate of complications requiring additional surgery. The average time from initial surgery to implant repair was 7.3 years, and Swanson's joints were more likely to last longer.

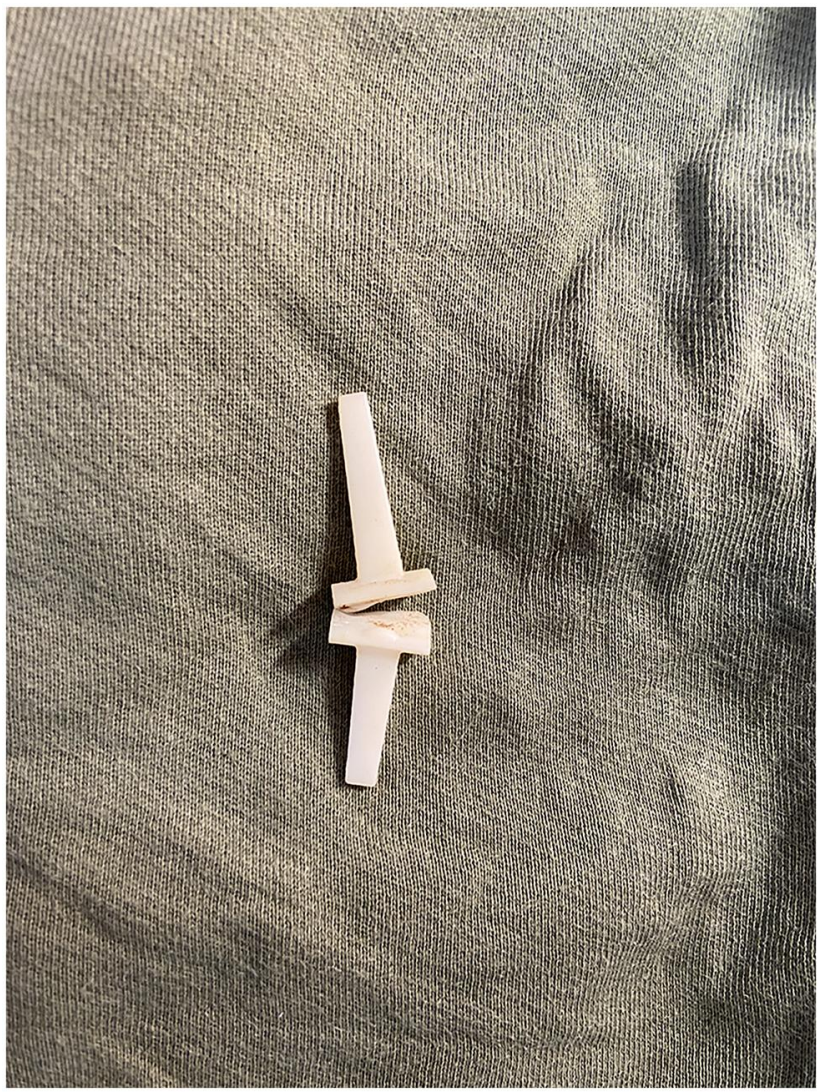

Figure 7 Typical implant fracture models in group B.

Previous studies have raised concerns about the durability of Swanson's arthroplasty. Swanson's joint replacement failure occurs due to the lack of anatomical rotation centers, high friction coefficients of the mechanism, metal fragments, loosening, cortical penetration, deposition and fractures. ${ }^{6,19,20}$ We thought that the reason for implant fracture may be related to direction of finger movement, because of two different fracture lines found during the revision operation. Although Swanson's arthroplasty has obvious short- and medium-term benefits for both rheumatoid and nonrheumatoid patients, ${ }^{5,8,17}$ the long-term

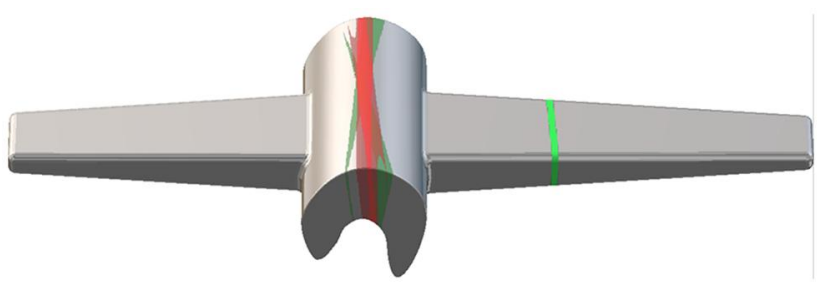

Figure 8 Stress model; The green line is the fracture position of the implant in group B, and the red line is in group A. The darker the color, the more frequent fractures. 
results of Swanson's arthroplasty have yet to be revealed, especially in traumatic conditions, and no studies have reported these results this in a large study population. For the first time, in our study, a joint orthosis was used to protect the finger, We think that the implant fracture and lateral stress may be related. Theoretically, this can increase the durability of the prosthesis because of the increased stress area, which is consistent with our results.

Swanson's arthroplasty can be used for traumatic fractures with bone defects. However, there are some conservative arguments, given the high risk of implant fractures and infections. ${ }^{9,21}$ We conducted a statistical analysis of the patients with implant fractures and found that Group A had worse radioulnar movement than Group B. There were no significant differences in the functional score between the two groups at postoperation. In addition, regarding the revision operation, we found that in the patients who wore the orthosis for a long period, the MCP joint scars were more obvious on both sides, but there were no differences in the extensor tendon scar between the two groups. The differences in implant fractures between the two groups may have also been due to scar adhesion. In a patient conservatively treated with a orthosis over a long period, the grip index did not decline significantly but the range of radioulnar movement decreased significantly. This finding may also be the result of wearing the joint orthosis for a long period.

When analyzing the failure implants, we found that in Group A, the broken ends were biased toward the horizontal type, but for patients in Group B, the broken ends were biased toward the oblique type (Figures 6 and 7). Both are stress fractures, but oblique fractures are mostly composite forces (from the direction of clamping force and flexion and extension), and transverse fractures are mostly single force (flexion and extension). Not only that, we found that Group B has a farther fracture end, while Group A have the opposite. This may be because the implant in the medullary cavity has greater resistance to flexion and extension, but less resistance to holding force.

Silicone implants have been successfully used in acute and posttraumatic MCP joint injuries. These semirestrictive implants have elastic silicone dynamic spacers to preserve finger alignment and balance and stability of the joint capsule, ligament, muscle and tendon system. Negle et $\mathrm{al}^{22}$ reported 14 cases of intra-articular bone MCP and proximal interphalangeal (PIP) fractures treated with silicone arthroplasty. This procedure has been proven to be a reliable alternative treatment for intra-articular, untreatable MCP fractures to preserve joint ROM. It is worth noting that DASH score is significantly linearly correlated with ROM and grip index, and we believe that ROM and grip index have the most significant impact on function (Figures 4 and 5). In our study, we noted the preservation of the MCP joint ROM, good pain relief and good functional recovery, suggesting that Swanson's arthroplasty may also be worth considering for the treatment of these MCP joint defects.

Implant fractures lead to loss of function, which is our primary consideration when using orthosis instead of arthroplasty alone. Langford et $\mathrm{al}^{23}$ showed that the distraction pinning technique provides reliable osseous union and joint stability of the metacarpal head. This technique is similar to our joint orthosis technique. Goldfarb et $\mathrm{al}^{24}$ reported the use of silicone implants in patients with rheumatoid arthritis, showing a bone fracture rate of $63 \%$. Although pyrolytic charcoal and other associated implants are available, they still need complete collateral ligaments for joint stability and are difficult to use in emergencies. The compatibility of silicone implants with tissue is good, but the rate of longterm fracture is still high. We think that the Swanson's joint is an attrition implant, and an implant fracture is a kind of stress fracture. Orthoses can only delay rather than prevent implant fractures. According to our follow-up results, the incidence of implant fracture was significantly lower in Group A than in Group B over the 3-year follow-up period, but implant fractures continued to occur.

In a particular case, the patient continued to wear a orthosis for seven years due to postoperative infection. There were no obvious signs of dysfunction, but there was almost no radioulnar movement. We believe that the reason may be that the Swanson's joints can work continuously for a long time when a joint orthosis is used.

In previous studies, ${ }^{5,25}$ patient function after arthroplasty was examined in patients with osteoarthritis. The average postoperative MCP ROM was 50 to $70^{\circ}$. However, arthroplasty can result in an average radian angle of 38 to $49^{\circ}$ in patients posttraumatic atonal arthritis. ${ }^{26}$ In our study, the patients had an average ROM $\left(53^{\circ}\right)$ at the follow-up, which is consistent with the results of previous studies on osteoarthritis. Although all injuries require extensor tendon repair, only a few patients experience ROM problems due to the rehabilitation protocol.

One-stage traumatic arthroplasty after an open wound is associated with a risk of infection and instability, and only 3 cases of these complications occurred in this study; the patients performed well after later modifications. The 
patient's conditions are important to consider when choosing one-stage arthroplasty. In this study, incised injuries were often sufficiently debrided during arthroplasty, base on our experiences. However, we do not encourage the use of such procedures in cases of severe contamination or skin viability problems. Adequate tendon repair is critical for providing stability. During the operation, the joint capsules were pulled back with sutures to make the joint capsules embedded in both sides of the implant. As a result, postoperative treatments emphasize flexion movements, which may limit radioulnar deviations after immobilization.

As stated earlier, fractures may occur during surgery due to the pressure associated with these implants. There is no need to stop the operation when a fracture occurs during the operation. Previous reports have shown that fractures during arthroplasty do not affect long-term survival. ${ }^{6}$

In acute traumatic conditions, arthroplasty should be considered to restore movement, strength and comfort. We recommend using Swanson's arthroplasty in open wounds that do not require extensive debridement and have enough soft tissue to cover the implants; moreover, when cutting through the smallest bones, it is important to keep the ligament inserted and prevent intraoperative fractures. If the collateral ligament is repaired or severely damaged, we recommend that the artificial joints are replaced in stages. We recommend using joint orthosis to limit radioulnar movement after operation. This may affect the abduction angle, but it will not affect the postoperative function, as shown in Figures 4 and 5, Postoperative function mainly depends on grip index and MCP joint ROM.

The study has several limitations. This study is a retrospective study and can not completely eliminate bias. Secondly, in terms of grouping, the quasi-random method is used, and the preoperative data is not perfect, not all patients were followed up, which could lead to artificial bias. Second, the data were retrieved from a single center, and there is a lack of multicenter research. When assessing the implant fractures, we looked at only whether the patient had lost function, not whether there was a clear fracture; in addition, we thought there might be some hidden fractures that could not be displayed by radiography without significant functional changes, but that did not change our findings.

\section{Conclusion}

The effect of Swanson's arthroplasty for bone loss at MCP joint is useful. The radioulnar stress may be the reason for implant fracture. In addition, Joint orthosis may be useful to protect implant fractures. Stress models show that the broken ends were biased toward the horizontal type in patients with joint orthoses and broken ends were biased toward the oblique type in patients without orthoses.

\section{Ethical Approval}

This study was approved by the Ethics Committee at Fuzhou Second Hospital Affiliated to Xiamen University (approval No: FZSE2020-10-18001). We obtained written informed consent from all participants involved in the study and conducted the study in compliance with the ethical principles for medical research involving human subjects in the Declaration of Helsinki.

\section{Author Contributions}

All authors made a significant contribution to the work reported, whether that is in the conception, study design, execution, acquisition of data, analysis and interpretation, or in all these areas; took part in drafting, revising or critically reviewing the article; gave final approval of the version to be published; have agreed on the journal to which the article has been submitted; and agree to be accountable for all aspects of the work.

\section{Funding}

There is no funding source.

\section{Disclosure}

The authors declare that they have no conflicts of interest.

\section{References}

1. Rizzo M. Metacarpophalangeal joint arthritis. J Hand Surg Am. 2011;36(2):345-353. doi:10.1016/j.jhsa.2010.11.035

2. Billig JI, Nasser JS, Chung KC. National prevalence of complications and cost of small joint arthroplasty for hand osteoarthritis and post-traumatic arthritis. J Hand Surg Am. 2020;45(6):551-553. doi:10.1016/j.jhsa.2019.11.002

3. Elherik FK, Dolan S, Antrum J, Unglaub F, Howie CR, Breusch SJ. Functional and patient-reported outcomes of the Swanson metacarpo-phalangeal arthroplasty in the rheumatoid hand. Arch Orthop Trauma Surg. 2017;137(5):725-731. doi:10.1007/s00402-017-2675-1

4. Sierakowski A, Zweifel C, Sirotakova M, Sauerland S, Elliot D. Joint replacement in 131 painful osteoarthritic and post-traumatic distal interphalangeal joints. J Hand Surg Eur. 2012;37(4):304-309. doi: $10.1177 / 1753193411422679$

5. Dickson DR, Badge R, Nuttall D, et al. Pyrocarbon metacarpophalangeal joint arthroplasty in noninflammatory arthritis: minimum 5-year follow-up. J Hand Surg Am. 2015;40(10):1956-1962. doi:10.1016/j. jhsa.2015.06.104

6. Houdek MT, Wagner ER, Rizzo M, Moran SL. Metacarpophalangeal joint arthroplasty in the setting of trauma. J Hand Surg Am. 2015;40 (12):2416-2420. doi:10.1016/j.jhsa.2015.09.012 
7. Pomares G, Calafat V, Montoya-Faivre D, Dap F, Dautel G. Emergency metacarpophalangeal arthroplasty with bone grafting for traumatic joint destruction. Orthop Traumatol Surg Res. 2017;103 (7):1105-1108. doi:10.1016/j.otsr.2017.07.007

8. Boe C, Wagner E, Rizzo M. Long-term outcomes of silicone metacarpophalangeal arthroplasty: a longitudinal analysis of 325 cases. $J$ Hand Surg Eur. 2018;43(10):1076-1082. doi:10.1177/ 1753193418778461

9. Joyce TJ, Giddins G. Sites of fractures in explanted NeuFlex(R) silicone metacarpophalangeal joint prostheses. J Hand Surg Eur. 2018;43(10):1083-1087. doi:10.1177/1753193418774500

10. Roh YH, Hong SW, Gong HS, Baek GH. Prognostic factors for nonsurgically treated sagittal band injuries of the metacarpophalangeal joint. J Hand Surg Am. 2019;44(10):891-897. doi:10.1016/j. jhsa.2018.11.011

11. Swanson AB. Flexible implant resection arthroplasty. Hand. 1972;4 (2):119-134. doi:10.1016/0072-968x(72)90030-7

12. Melone CJ, Dayan E. Articular surgery of the ischemic hand in systemic scleroderma: a vascular basis for arthrodesis and arthroplasty. J Hand Surg Am. 2018;43(6):571-574. doi:10.1016/j. jhsa.2018.03.008

13. Morrell NT, Weiss AC. Silicone metacarpophalangeal arthroplasty for osteoarthritis: long-term results. J Hand Surg Am. 2018;43 (3):229-233. doi:10.1016/j.jhsa.2017.10.010

14. Srnec JJ, Wagner ER, Rizzo M. Implant arthroplasty for proximal interphalangeal, metacarpophalangeal, and trapeziometacarpal joint degeneration. J Hand Surg Am. 2017;42(10):817-825. doi:10.1016/ j.jhsa.2017.07.030

15. Petscavage JM, Ha AS, Chew FS. Arthroplasty of the hand: radiographic outcomes of pyrolytic carbon proximal interphalangeal and metacarpophalangeal joint replacements. AJR Am J Roentgenol. 2011;197(5):1177-1181. doi:10.2214/AJR.10.5862

16. Bachleitner K, Blank B, Klein S, et al. Vascularized transfer of two coherent toe joints in simultaneously reconstructing MCP and PIP of a mutilated finger. Clin Hemorheol Microcirc. 2016;64(3):333-344. doi: $10.3233 / \mathrm{CH}-168100$

17. Chung KC, Burns PB, Kim HM, Burke FD, Wilgis EF, Fox DA. Long-term followup for rheumatoid arthritis patients in a multicenter outcomes study of silicone metacarpophalangeal joint arthroplasty. Arthritis Care Res. 2012;64(9):1292-1300. doi:10.1002/acr.21705
18. Neral MK, Pittner DE, Spiess AM, Imbriglia JE. Silicone arthroplasty for nonrheumatic metacarpophalangeal joint arthritis. $J$ Hand Surg Am. 2013;38(12):2412-2418. doi:10.1016/j.jhsa.2013.09.016

19. Wagner ER, Demark RR, Wilson GA, Kor DJ, Moran SL, Rizzo M. Intraoperative periprosthetic fractures associated with metacarpophalangeal joint arthroplasty. J Hand Surg Am. 2015;40(5):945-950. doi:10.1016/j.jhsa.2014.12.038

20. Wagner ER, Houdek MT, Packard B, Moran SL, Rizzo M. Revision metacarpophalangeal arthroplasty: a longitudinal study of 128 cases. J Am Acad Orthop Surg. 2019;27(6):211-218. doi:10.5435/JAAOSD-17-00042

21. Zhang H, Xue D, Yu J. Is Swanson prosthesis better than Sutter prosthesis for metacarpophalangeal joint arthroplasty? A meta-analysis. J Plast Surg Hand Surg. 2015;49(1):45-51. doi:10.3109/2000656X.2014.942313

22. Nagle DJ, Af EF, Lister GD. Immediate silastic arthroplasty for non-salvageable intraarticular phalangeal fractures. Scand J Plast Reconstr Surg Hand Surg. 1989;23(1):47-50. doi:10.3109/ 02844318909067508

23. Langford MA, Cheung K, Li Z. Percutaneous distraction pinning for metacarpophalangeal joint stabilization after blast or crush injuries of the hand. Clin Orthop Relat Res. 2015;473(9):2785-2789. doi:10.1007/s11999-015-4233-x

24. Goldfarb CA, Stern PJ. Metacarpophalangeal joint arthroplasty in rheumatoid arthritis. A long-term assessment. J Bone Joint Surg Am. 2003;85(10):1869-1878. doi:10.2106/00004623-20031000000001

25. Parker WL, Rizzo M, Moran SL, Hormel KB, Beckenbaugh RD. Preliminary results of nonconstrained pyrolytic carbon arthroplasty for metacarpophalangeal joint arthritis. J Hand Surg Am. 2007;32 (10):1496-1505. doi:10.1016/j.jhsa.2007.09.005

26. Foucher G, Hoang P, Citron N, Merle M, Dury M. Joint reconstruction following trauma: comparison of microsurgical transfer and conventional methods: a report of 61 cases. J Hand Surg Br. 1986;11(3):388-393. doi:10.1016/0266-7681(86)90164-6
Journal of Pain Research

\section{Publish your work in this journal}

The Journal of Pain Research is an international, peer reviewed, open access, online journal that welcomes laboratory and clinical findings in the fields of pain research and the prevention and management of pain. Original research, reviews, symposium reports, hypothesis formation and commentaries are all considered for publication. The manuscript management system is completely online and includes a very quick and fair peer-review system, which is all easy to use. Visit http:// www.dovepress.com/testimonials.php to read real quotes from published authors. 